\title{
Discussion: Rationalising assessment approaches for masonry arch bridges
}

Niamh Gibbons

Research Associate, Centre for Smart Infrastructure and Construction, Department of Engineering, University of Cambridge, UK
Paul J. Fanning

Senior Lecturer, School of Civil, Structural and Environmental Engineering, University College Dublin, Dublin, Ireland

Bill Harvey

Bill Harvey Associates Ltd, Exeter, UK

\section{Contribution by Bill Harvey}

Papers of this type take a deal of work and considerable thought (Gibbons and Fanning, 2012). The authors are to be thanked for their efforts.

The contributor wishes to take issue with two statements they make before raising his main point. In Section 2.2.2 the authors state that the Ring program (which is not the contributor's), being based on the formation of four plastic hinges, can be considered as an upper bound solution. This is a misreading of the plastic theorems. Ring satisfies both the mechanism and the equilibrium conditions, and indeed as it considers material strength, the yield condition. It is therefore simultaneously an upper and lower bound solution within its own boundaries. Displacement is, of course, not considered.

In Section 2.3.2 the authors discuss the use of a threedimensional (3D) finite-element model and yet say they treat the load as distributed laterally over $3 \mathrm{~m}$. The contributor simply does not understand that.

That the authors' conclusion that military engineering experimental establishment (MEXE) has no value is no surprise. It is no quicker than many modern approaches and has no demonstrable connection with bridge behaviour. That it appears at all in the latest versions of BA16 and BD21 is inexcusable. The authors may not be aware that a different version of MEXE is used by the railways, in which gross errors were added to the computations in the 1970s. The railway version is therefore yet more optimistic about behaviour.

Assessment, though, is not all about analysis. Indeed, in the current state of understanding, analysis should play but a small part, leavened with a serious dose of engineering judgement by an experienced engineer. The distribution models used in all methods to convert a 3D problem into a two-dimensional (2D) model are deeply flawed, as is evident from a modest study of Davey's results from the 1930s. If an effective strip model is viable, it should certainly not be based solely on the depth of fill.
In any case, ultimate behaviour is of no real interest when very serious economic consequences result from deterioration without any approach towards collapse.

BA16 presents results from the 1980s tests as correct. They are mostly not even valid in their own terms. A mistaken attempt was made to test the bridges as $2 \mathrm{D}$ structures, and the result was that the loading system became part of the structure being tested. Most of the results are grossly inflated as ultimate loads. BD21/01 says in annex $\mathrm{H}$, clause $\mathrm{H} 1$

Examination of typical load deformation curves from the ten TRL tests (Ref 10), a few examples of which are given in Figure H1, shows that deformations increase rapidly as the applied load exceeds approximately half the ultimate failure load. In order to avoid causing any permanent structural damage, therefore, it will be prudent to limit regularly applied loading, pending a detailed investigation regarding serviceability, to half the ultimate failure load.

In fact, the load deflection curves are not continuous curves but multilinear. In most, there is a marked change of slope substantially below the half ultimate load and that change of slope indicates a point of no return beyond which damage is being done.

In short, engineers have a long way to go before they can offer proper, rational assessment of masonry bridges. This paper is a worthwhile contribution but much further work is needed.

\section{Authors' reply}

The authors wish to thank Dr Bill Harvey for his interest in the paper and his constructive criticism.

Essentially the authors would view the work in this paper as a step along the way towards a hierarchical assessment framework of which the ultimate capacity behaviour is only a part. From a practical point of view, rightly or wrongly, analysis of the ultimate capacity failure load is currently the most widely 
applied means of assessment and the main focus of the existing codes of practice. The central tenet of the paper was to outline the assumptions and hence the limitations of differing analysis methods and subsequently to rationalise the relationship between them with regard to the assessed load capacities.

The authors would agree that the real point of interest is not in the ultimate behaviour, but in the proceeding damage and associated change in stiffness that is initiated at much lower loads. As the contributor discussed, much more telling information is available in load deflection responses than in reported ultimate capacity failure loads - behaviour beyond the scope of the analysis methods discussed in this paper.

The authors welcome the clarification regarding the Ring software program, which allows for consideration of both an upper bound solution satisfying equilibrium and mechanism conditions, and a lower bound solution satisfying equilibrium and yield conditions. With regard to the transverse load distribution for the 3D analysis, no fill elements were included and the fill was accounted for only as a dead load weight. Therefore, assumptions regarding load distribution of the live loads through the fill material were required. The $3 \mathrm{~m}$ width relates only to the transverse distribution through the fill material and not to the load distribution that occurs in the arch barrel itself.

\section{REFERENCE}

Gibbons N and Fanning PJ (2012) Rationalising assessment approaches for masonry arch bridges. Proceedings of the Institution of Civil Engineers - Bridge Engineering 165(3): 169-184, http://dx.doi.org/10.1680/bren.11.00023.

\section{WHAT DO YOU THINK?}

To discuss this paper, please email up to 500 words to the editor at journals@ice.org.uk. Your contribution will be forwarded to the author(s) for a reply and, if considered appropriate by the editorial panel, will be published as discussion in a future issue of the journal.

Proceedings journals rely entirely on contributions sent in by civil engineering professionals, academics and students. Papers should be 2000-5000 words long (briefing papers should be 1000-2000 words long), with adequate illustrations and references. You can submit your paper online via www.icevirtuallibrary.com/content/journals, where you will also find detailed author guidelines. 